\title{
SIMULAÇÃO DE EM QUARTEIRÕES COMPARATIVA DOS VISIBILIDADE CITYENGINE E CITYZOOM HISTÓRICOS:
} ANÁLISE

Visibility and occlusion simulation in conservation areas: comparative analysis of ArcGIS, CityEngine and Cityzoom software

\section{Benamy Turkienicz', Guilherme Kruger Dalcin', Rodrigo Pereira Lersch', Renato Sil- veira'}

RESUMO: A equilibrada coexistência entre novas construções e conjuntos históricos costuma ajudar a preservar ambiências urbanas e a reforçar o protagonismo de edifícios de inegável valor plástico e cultural. Muitas vezes, restrições construtivas originadas em descrições subjetivas do espaço urbano geram excessos indesejáveis como a redução da atratividade de investimentos e a estagnação das relações sociais e econômicas existentes nestes lugares. Nos dias de hoje, ferramentas computacionais e tecnologias de visualização podem ser utilizadas para aumentar a percepção sobre limiares de interferência visual de novas construções sobre edificações históricas e, se criteriosamente utilizadas, podem contribuir para subsidiar a análise objetiva de impactos urbanísticos conferindo celeridade ao licenciamento das novas construções. Modelos computacionais podem ser utilizados para descrever, numérica e graficamente, espaços oclusos de áreas históricas e "mapear" a interferência de novas edificações. Tecnologias utilizadas para edição de projetos de arquitetura hoje disponíveis não oferecem este mapeamento: este artigo compara o desempenho de ferramentas computacionais que utilizam conceitos elementares de oclusão e visibilidade na aferição de impactos visuais urbanos. A comparação tem por objetivo diferenciar características funcionais destas ferramentas para representar e mensurar espaços dentro e fora dos campos visuais de transeuntes. O trabalho se divide em quatro partes. A primeira parte descreve os modelos conceituais de oclusão e visibilidade e suas aplicações computacionais em três softwares escolhidos para a análise comparativa: ArcGIS, CityEngine e Cityzoom. A segunda parte apresenta os métodos utilizados pelos três softwares para simulação e mensuração de "envelopes oclusos" em quarteirões históricos. Os métodos são testados, na terceira parte, em estudo de caso constituído por quadras do Centro Histórico da cidade de Pelotas - RS. Os resultados obtidos mostram diferenças entre modelos de dados: ArcGIS e CityEngine computam as partes visíveis dos volumes existentes, enquanto Cityzoom computa volumes virtuais em oclusão. Se os três softwares analisados contribuem para a aferição do impacto de novas edificações em ambiente urbano contendo edificações históricas, o software Cityzoom permite a modelagem e mensuração automática, conferindo maior rapidez de resposta em relação aos dois outros softwares.

PALAVRAS-CHAVE: Oclusão; Visibilidade; Ambiência Histórica; Cidades Históricas.

\begin{abstract}
Adequate coexistence between new buildings and historic buildings usually favours historical heritage and help to reinforce the protagonist role of buildings with acknowledged plastic and cultural value. Often, urban regulations constraints originated in subjective interpretations of the urban environment do generate undesirable excesses thus reducing investments and freezing the development of existing social and economic networks. Computational tools and visualization technologies can nowadays be used to enhance the perception about the positive and negative visual interference of new buildings on historical sites and, if judiciously used, can contribute to the objective assessment of urban visual impacts. Computational models can be used to numerically and graphically describe occluded volumes and to "map" the interference of new buildings in preservation areas. Available technologies conventionally used for architectural design do not offer this mapping functionality but CIM (City Information Modelling) software do. This article compares the performance of CIM tools using elementary concepts of occlusion and visibility to measure visual impacts of urban scenarios. The comparison aims to differentiate functional characteristics of these tools to represent and measure spaces within and outside the visual reach of pedestrians. The work is divided into four parts. The first part describes the conceptual models of occlusion and visibility and their computational applications in three software chosen for comparative analysis: ArcGIS, CityEngine and Cityzoom. The second part presents the methods used by the three software for simulation and measurement of "occluded envelopes" in preservation areas. The methods are tested, in the third part, in a case study consisting of blocks located in the Historical District of the city of Pelotas, Brazil. The assessment revealed differences between data models: ArcGIS and CityEngine compute the visible parts of existing volumes while Cityzoom computes virtual occluded volumes. While the three analysed software contribute to the impact assessment of new buildings, Cityzoom enables the automatic modelling and measurement of virtual occluded volumes, thus offering the user a faster assessment than the two other software.
\end{abstract}

KEYWORDS: Occlusion; Visibility; Urban Ambience; Historical Cities.

TURKIENICZ, B.; DALCIN, G. K.; LERSCH, R. P.; SILVEIRA, R. Simulação de visibilidade e oclusão em quarteirões históricos: análise comparativa dos softwares Arcgis, Cityengine e Cityzoom. Gestão e Tecnologia de Projetos, São Carlos, v.15, n.1, p.83-100, jan.2020. http://dx.doi.org/10.116/gtp.v14i1.152820

Fonte de financiamento:

Conflito de interesse:

Submetido em: Aceito em: 


\section{INTRODUÇÃO}

Edifícios e espaços urbanos antigos, quando preservados, colaboram para consolidar a identidade e a memória coletiva de uma cultura ou de uma sociedade. A forma com que edificações estabelecem relações espaciais com ruas, avenidas e praças pode dar suporte a diferentes atividades sociais e econômicas de uma comunidade. Por criarem referenciais de identidade cultural e constituírem suporte de atividades sociais e econômicas, edificações e espaços urbanos antigos constituem fortes atrativos tanto para moradores como para visitantes de centros urbanos. Grandes modificações introduzidas na ambiência urbana através de prédios novos ou demolição de prédios antigos podem reduzir atrativos que motivam residentes e turistas a percorrerem espaços urbanos de centros e bairros históricos.

A manutenção do legado cultural edificado exige que a introdução de novas edificações em áreas de preservação histórica seja feita de forma cuidadosa. São, por isto, de fundamental importância as análises que conseguem prever e avaliar o impacto das novas edificações para que não comprometam a ambiência histórica de um local. Quando construídas de forma inadequada, edificações vizinhas a prédios históricos podem determinar efeitos indesejáveis, muitas vezes rompendo a percepção de um conjunto urbano.

A caracterização dos fatores ou elementos do espaço edificado que constituem uma ambiência urbana é tarefa complexa, dadas as múltiplas possibilidades da percepção humana. Como aponta Fraccaroli (1982), “[...] Se o todo é mais do que a soma das partes, uma determinada pessoa que visualiza um conjunto de elementos 'a' e um conjunto de elementos 'b' separadamente não obtém a mesma percepção que a pessoa que vê ' $a+b$ '”. A interação entre os elementos gera uma terceira situação, que se pode chamar de "c". Esta só existe pela correlação entre as anteriores. Uma vez somados, não é possível distinguir "a" e "b", mas o que se percebe é uma nova realidade. Esta relação que define os fatores que criam e recriam ambiências urbanas levou instituições responsáveis pela preservação do patrimônio edificado a considerar não só a importância do edifício de excepcional arquitetura, mas, também, edifícios de arquitetura modesta que, em conjunto com o excepcional, configuram conjunto arquitetônico ou ambiência urbana de excepcional valor imagético.

Com intuito de preservar a integridade visual de conjuntos de prédios históricos, estratégias preservacionistas sugerem a construção de novas edificações "atrás" da edificação antiga para preservar a continuidade da ambiência urbana (SIQUEIRA, 2017). Se tais estratégias atingem, em vários casos, seus objetivos, produzem efeitos indesejados em outros. Isto sucede quando um novo edifício rompe o conjunto urbano e provoca "achatamento" do prédio histórico, que é traduzido pela predominância da construção nova sobre as construções antigas. A inclusão de um edifício de porte avantajado em ambiente caracterizado por edifícios de baixo porte leva o transeunte a "trocar" de referencial: uma edificação antiga, antes caracterizada como a principal protagonista deste espaço urbano, pode se tornar mera coadjuvante se tiver, na sua vizinhança perceptível, outra edificação de porte mais avantajado. A Figura 1 demonstra, com dois exemplos para a cidade de Porto Alegre, o impacto que edificações antigas podem sofrer quando da construção de edifícios de grande porte na parte posterior de seus lotes. 

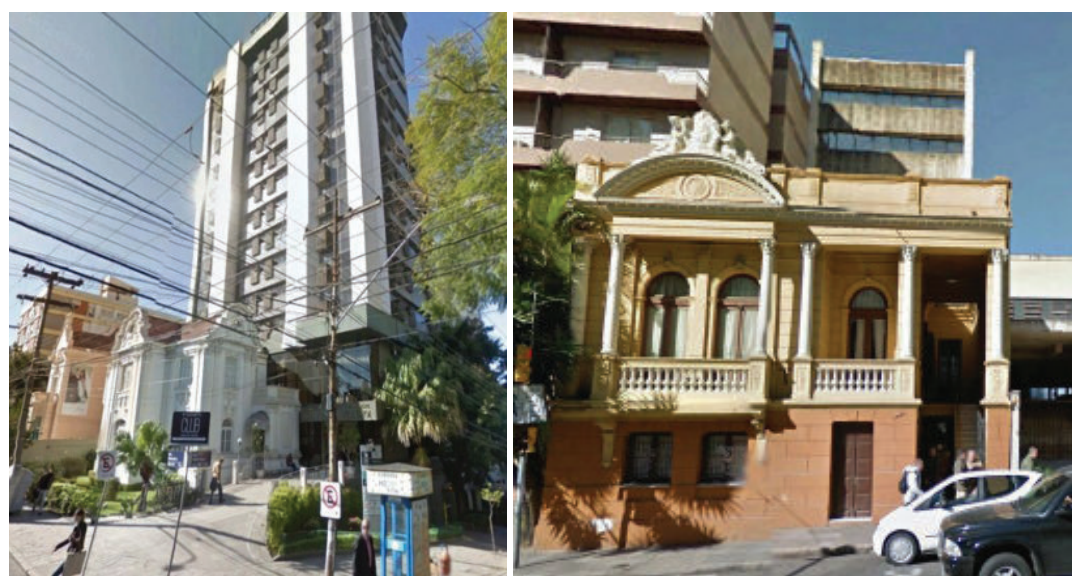

Figura 1: Edificações novas construidas na parte posterior de exemplares históricos

Fonte: Google Street View.
O risco da alteração no protagonismo de edifícios históricos em cenários urbanos brasileiros levou o Instituto do Patrimônio Histórico e Artístico Nacional (IPHAN) a desenvolver diretrizes e normas que subsidiam restrições do potencial construtivo de lotes vizinhos a prédios históricos. A portaria 10 (IPHAN, 1986) prescreve a necessidade de avaliação técnica para a introdução de edificação nova ou alteração de características originais em áreas urbanas possuidoras de bens de valor histórico. De acordo com a mesma portaria, intervenções em áreas históricas devem envolver acompanhamento pelos órgãos do poder municipal competente e subsequente encaminhamento à diretoria regional da Secretaria do Patrimônio Histórico e Artístico Nacional (SPHAN) para sua possível aprovação. A Normatização de Cidades Históricas (IPHAN, 2011) prescreve poligonais de tombamento nas quais não são admitidas quaisquer alterações. $\mathrm{O}$ tombamento por poligonais de preservação é feito quando se avalia: a) que uma determinada área possui volume considerável de edificações conservadas e b) que a contiguidade destas edificações cria uma relação de ambiência que traduz valor histórico.

Restrições excessivas impostas sobre novas construções nos centros e bairros históricos podem, também, levar ao "congelamento" ou estagnação de relações sociais e econômicas existentes nestes lugares. Como resultado, muitos centros e bairros históricos convertem-se em verdadeiros museus a céu aberto: abandonados pela população, passam por acelerado processo de deterioração.

Uma alternativa para a reprodução de atividades econômicas e da manutenção de população residente em centros e bairros históricos está vinculada, necessariamente, ao restauro, reforma e mesmo à construção de novas edificações. Dadas as imposições de manutenção da imagem urbana a partir do usuário do espaço público, a construção de novas edificações fica condicionada às possibilidades oferecidas por lotes urbanos de abrigar edificações cuja volumetria não cause impactos visuais indesejáveis. Ferramentas computacionais que permitam indicar limiares de interferência visual na ambiência produzida por edificações históricas ou até mesmo volumes que não serão visualizados por nenhum transeunte - são de fundamental importância para a análise e licenciamento de novas construções, bem como para fundamentar em critérios objetivos o debate, envolvendo técnicos e público leigo, em torno de propostas projetuais em ambientes históricos.

Se de um lado as normativas brasileiras que regem a autorização de novas edificações em centros e bairros históricos são claras em seus objetivos de preservação de ambiências urbanas, por outro lado inexistem no Brasil parâmetros de aferição de impacto para a concessão de autorizações para edificações novas em centros e bairros históricos. No País, é também escassa a oferta de trabalhos científicos que descrevem a utilização de ferramentas de visualização urbana para simulação e quantificação de aspectos referentes à inserção de novas construções em centros e bairros históricos. 
Menor ainda é a incorporação, por parte das instituições responsáveis pelo regramento de ambiências urbanas com relevância histórica, de modernas técnicas de análise de impacto de novas edificações.

Trabalhos produzidos por Escorteganha et al. (2012) e Teodoro et al. (2012) descrevem técnicas de visualização voltadas à preservação do patrimônio histórico, porém pouco enfocam os impactos de edificações novas sobre a visualização de exemplares históricas. A carência de utilização de tecnologias de visualização pode ser considerada um paradoxo, tendo em vista a oferta, no mercado, de diferentes ferramentas computacionais capazes de simular campos visuais de um observador alocado em posições fixas de percursos do espaço urbano e aferir, em sequência, a interferência visual produzida por edificações novas ou por alterações de edificações existentes.

Sistemas de Informações Geográficas (SIG), como o ArcGIS - plataforma de mapeamento e análise geolocalizada (ARCGIS, 2018) - e o CityEngine software para geração procedural de modelos geométricos de ambientes urbanos (CITYENGINE, 2018) - têm contribuído para a avaliação visual (CÂMARA; DAVIS, 2001) e, portanto, para a aferição do volume referente a espaços não vistos por observador localizado em torno de áreas com edificações históricas. A descrição das relações de visibilidade entre edificações existentes e propostas em quadras urbanas são já executadas através do Cityzoom, ambiente computacional de modelagem e simulação de apoio à arquitetura e ao urbanismo, desenvolvido pelo Laboratório de Simulação e Modelagem em Arquitetura e Urbanismo (Simmlab) e pelo Núcleo de Tecnologia Urbana (NTU) da Universidade Federal do Rio Grande do Sul (TURKIENICZ; GONÇALVES; GRAZZIOTIN, 2008).

Este trabalho descreve funcionalidades dos softwares ArcGIS, CityEngine e Cityzoom que podem oferecer suporte à aferição de volumes potencialmente oclusos de quadras configuradas por conjuntos históricos e à simulação de diferentes graus de visibilidade tolerada para estes volumes. Essas funcionalidades poderiam contribuir para conferir objetividade e eficiência ao licenciamento de novas edificações em quarteirões históricos ao a) facilitar o mapeamento dos espaços passíveis de serem construídos sem causar qualquer interferência às visuais dos exemplares históricos, b) fornecer a representação dos efeitos causados por tolerâncias ao grau de visibilidade de novas construções e c) informar as medidas quantitativas correspondentes ao potencial construtivo dos volumes simulados.

A comparação dos softwares leva em conta a) a capacidade dos modelos icônicos de representar a visão do observador; b) a rapidez do processo de cada software, indicativo da agilidade com que simulações podem ser executadas para informar debates; e c) as medidas quantitativas do potencial construtivo das simulações, as quais explicitam a acurácia dos modelos computacionais dos softwares analisados.

Para tanto, este artigo se divide em quatro partes: na primeira, são descritos os modelos de oclusão que fundamentam as três ferramentas estudadas; a segunda parte é constituída pela descrição de processos de análise visual pertinentes a cada ferramenta; na terceira parte, tais processos são testados em dois quarteirões do município de Pelotas - RS, constituídos por edificações listadas como de interesse para a preservação da ambiência oferecida pelo patrimônio histórico da cidade. No teste, todas as edificações são consideradas permanentes e são utilizados como variáveis para inserção de novos volumes edificados os parâmetros de altura e recuos de fundos obrigatórios constantes no Plano Regulador existente ${ }^{1}$; na parte final são apresentados resultados e conclusões do trabalho.

\section{Modelos de visibilidade e oclusão}

Na representação bidimensional de espaços visíveis e oclusos definida por Benedikt (1979), dada uma região $\boldsymbol{D}$ do espaço - limitada por uma superfície $\boldsymbol{S} \boldsymbol{l}$ - dentro da qual se localiza um ponto de observação $\boldsymbol{x}$ $\begin{array}{cc}1 & \text { Considerou-se apenas altura máxima e recuos mínimos porque, no Plano Regulador do município de Pelotas, estes } \\ \text { são os parâmetros que definem diretamente as áreas não construíveis de um lote. }\end{array}$ 
e superfícies materiais $\mathbf{S m}$, define-se isovista como sendo o conjunto de todos os pontos dentro de $\boldsymbol{D}$ visíveis a partir de x. Para um ponto ser visível, é necessário que nenhuma superfície - limítrofe ou material - esteja obstruindo a conexão direta entre ele e o ponto de observação. A partir disso, o espaço ocluso $\boldsymbol{V} \boldsymbol{x}$ é definido como toda a região dentro de $\boldsymbol{D}$ que não é visível do ponto de observação $\boldsymbol{x}$ e que não faz parte de uma superfície material. Como mostra a Figura 2, a isovista é definida apenas em duas dimensões e é representada através da vista superior do espaço ao redor do ponto $\boldsymbol{x}$, onde se posicionaria um observador com visão para todas as direções ao seu redor.

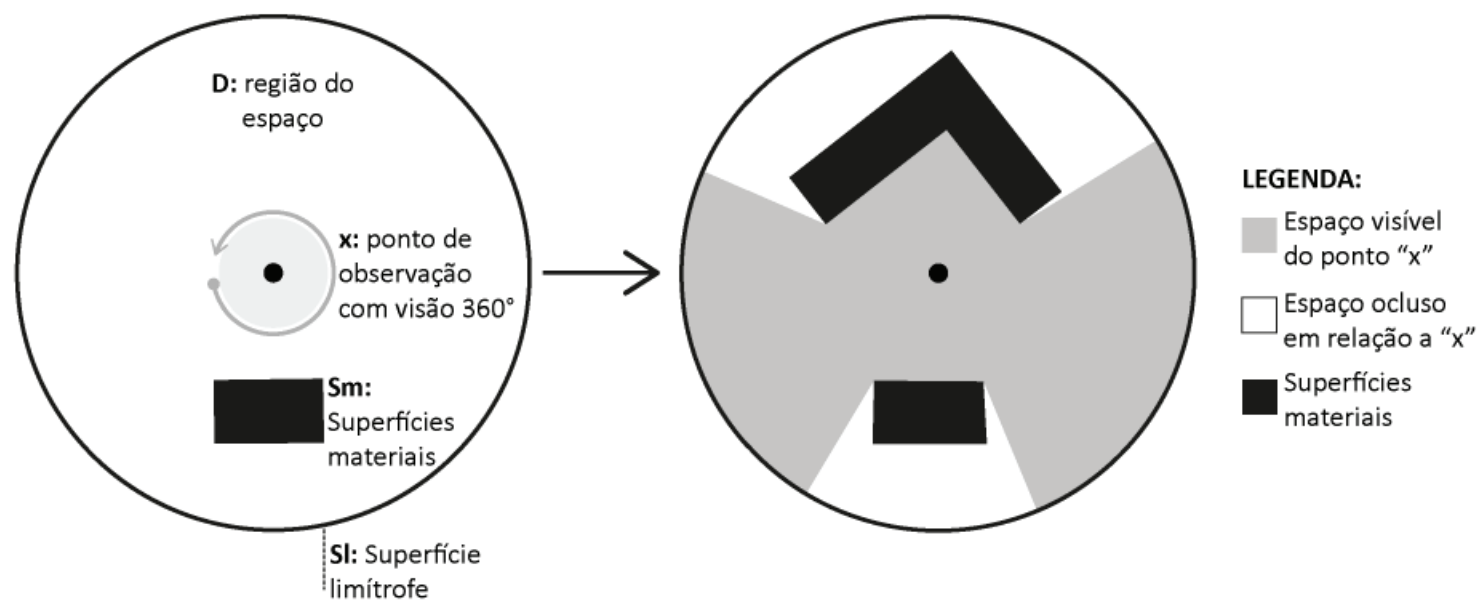

Figura

2: Definição de isovista

Fonte: Adaptada de Benedikt (1979, p. 49-50).

Essa definição também pode ser estendida para um conjunto de posições de modo a representar a visibilidade de um observador percorrendo determinado trajeto. Neste caso, as áreas visíveis das diversas isovistas são sobrepostas e o espaço abrangido por elas é considerada visível, enquanto as regiões não visualizadas a partir de nenhuma posição configuram o espaço ocluso (ver Figura 3). A definição de Benedikt (1979) é exclusivamente bidimensional. Logo, para a representação tridimensional torna-se necessário descrever a abrangência do campo de visão no sentido vertical. Considerando ângulo horizontal igual a $360^{\circ}$ e ângulo vertical igual a $180^{\circ}$, é obtida uma meia esfera representativa do espaço que pode ser visualizado pelo observador, com suas dimensões dadas pelo alcance máximo da visão do observador (Figura 4) (DALTON; DALTON, 2015; TELLER, 2003; THIEL, 1997).
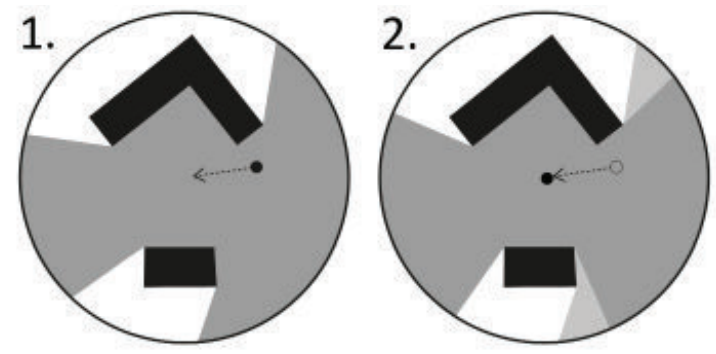

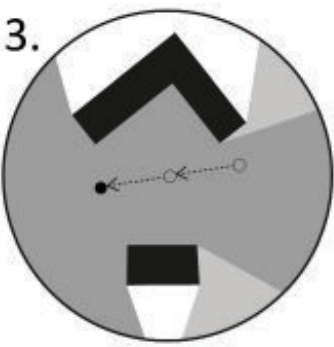

Áreas oclusas

Áreas visiveis na

posição atual do percurso

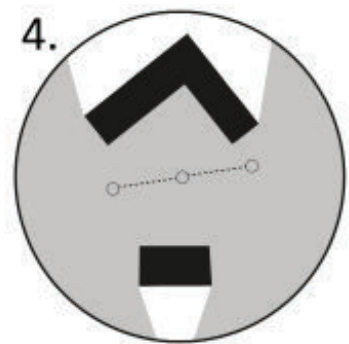

Áreas visiveis em posiçōes anteriores do percurso

Superfícies materiais

Figura 3: Isovista resultante do movimento do observador por múltiplos pontos de observação. O espaço visível corresponde à união dos espaços visíveis em cada ponto.

Fonte: Adaptada de Benedikt (1979, p. 51). 


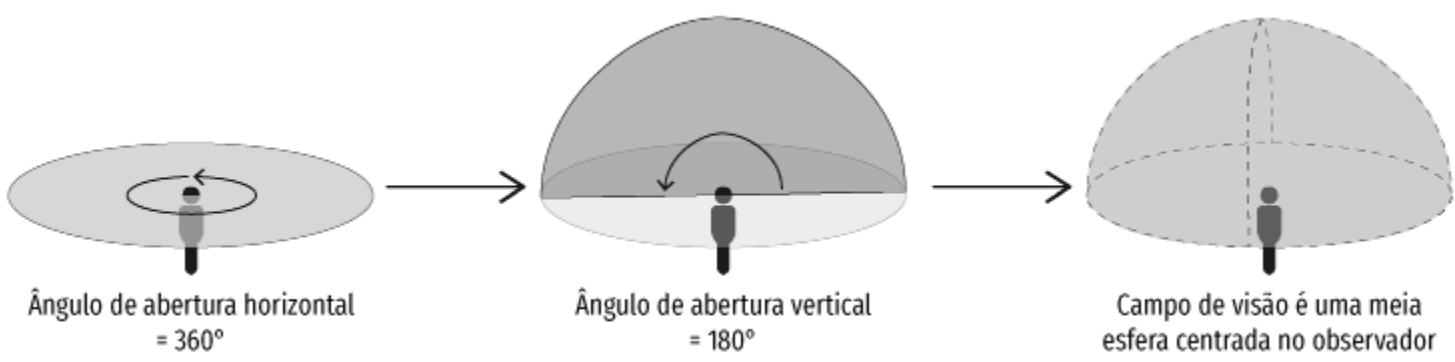

Figura 4: Campo visual tridimensional semiesférico.

Fonte: Elaborada pelo autor, com base em Dalton e Dalton (2015).

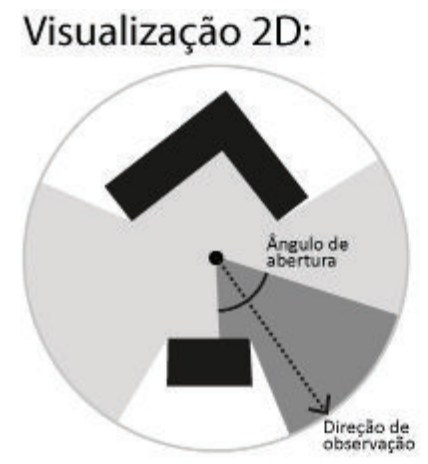

ArcGIS, CityEngine e Cityzoom utilizam o mesmo campo esférico como base da descrição de suas análises. Entretanto diferem no modo que discriminam espaço visível e ocluso. Cityzoom e CityEngine consideram uma direção de visualização específica e ângulos de abertura de campo visual do ser humano. Esta delimitação do campo visual determina campo de visão cônico - não esférico (Figura 5) - tornando ocluso o que está fora do alcance deste campo de visão em cada posição do percurso.

Neste quesito, Cityzoom se diferencia de CityEngine ao descrever a visibilidade/oclusão do espaço “vazio", registrando esses espaços e armazenando sua condição de visível/ocluso. Batty (2001) propôs que este registro fosse gerado a partir da subdivisão do espaço em módulos, representados por quadrados - no espaço bidimensional - ou cubos - no espaço tridimensional - com o centro de cada módulo sendo utilizado como referência para o cálculo da visibilidade de toda a região compreendida pelo módulo (Figura 6).

Figura 5: À esquerda, isovista com a delimitação de um campo de visão específico. À direita, cone de visão tridimensional. Fonte: Elaborada pelo autor.

A conversão dessa modularização para o espaço tridimensional implica na sobreposição do conjunto de pontos em novas camadas, originando nuvem de pontos na qual cada ponto é o centroide de um módulo espacial volumétrico. O espaço ocluso é computado através da verificação, para cada ponto da nuvem, se ele está contido no cone de visão do observador e se não existem obstáculos interrompendo a ligação visual entre ponto e observador. Os módulos cujos centroides são oclusos tornam-se visíveis, gerando representação volumétrica do espaço ocluso (Figura 7). 


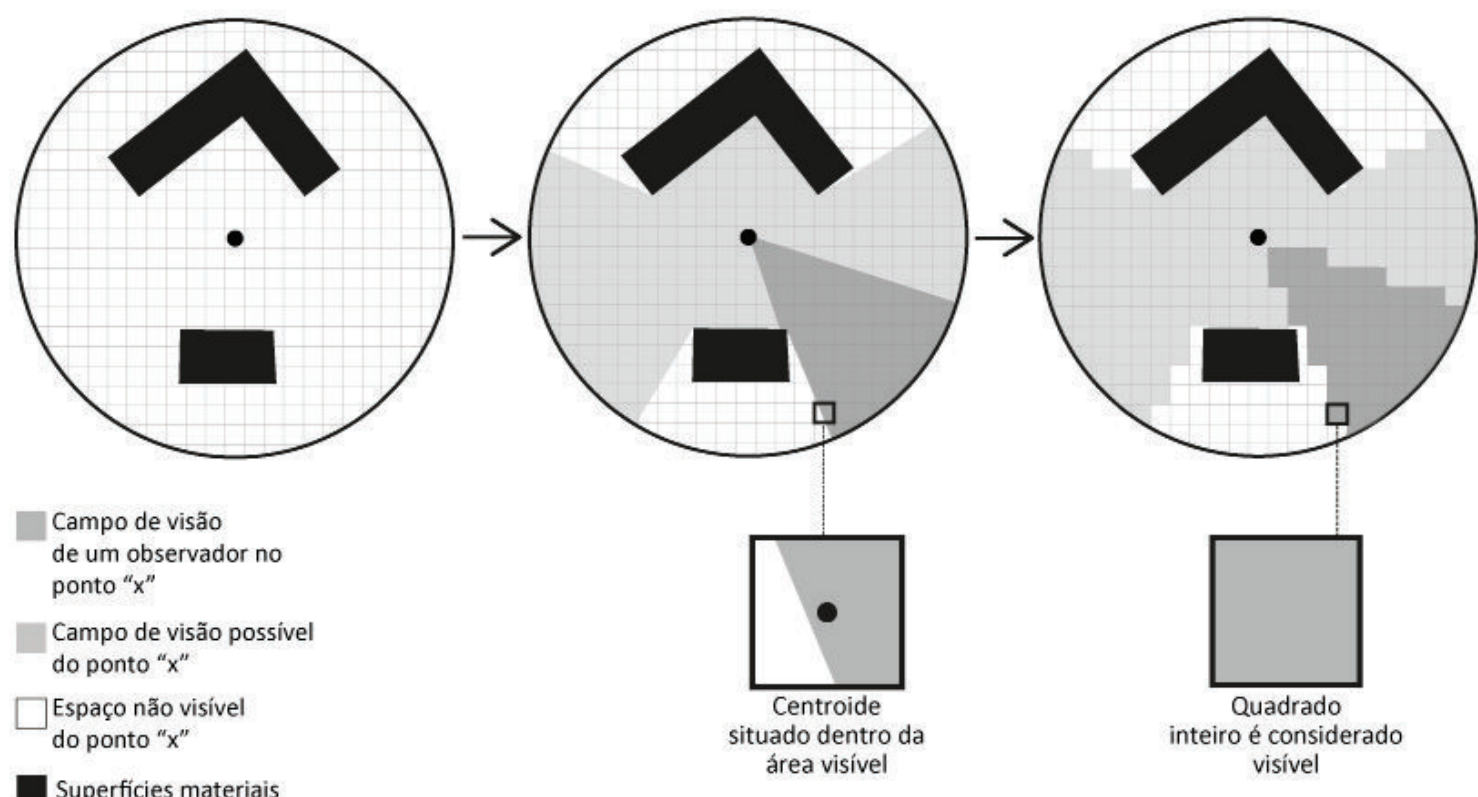

Figura 6: $O$ espaço é discretizado em células quadradas (módulos), tornando possível a representação de qualquer região do espaço. A classificação de cada célula se dá através da análise do seu centroide.

Fonte: Elaborada pelo autor, com base em Batty (2001).

O resultado fornecido pelo modelo computacional Cityzoom é, portanto, o volume não visível a partir de qualquer posição de observação do espaço público. Devido à discretização do espaço, este volume ocluso é gerado a partir do espaço livre ao redor das edificações. Suas subdivisões - os cubos gerados a partir da nuvem de pontos - permitem, por serem representação material do espaço, a aferição de medidas de desempenho em suas superfícies, tais como sombreamento e iluminação natural. Adicionalmente, este volume ocluso tem grau de visibilidade sujeito à variação controlada em que, para além do espaço de oclusão total, podem ser acrescentadas células visíveis até limites desejados, sendo o grau de visibilidade tolerada definido pela amplitude do ângulo vertical de visão. Isso permite que espaços localizados nos bordos do campo visual sejam toleráveis como não prejudiciais ao protagonismo dos prédios de valor histórico (Figura 8).

O software CityEngine, por outro lado, fornece a indicação, nas próprias superfícies do modelo, da informação sobre sua visibilidade/oclusão, de modo que a realização de análises depende da modelagem prévia de cenários de cidade contendo os objetos cuja oclusão se deseja aferir. A indicação da visibilidade das superfícies ocorre através da cromatização das regiões do objeto contidas no campo de visão de algum observador (Figura 9).

O software ArcGIS, apesar de possibilitar diversos tipos de análise de visibilidade e oclusão, possui apenas uma ferramenta que apresenta resultados para superfícies verticais e, portanto, úteis para análise de ambientes urbanos (SANDER; MANSON, 2007). A implementação computacional deste modelo não limita o campo de visão do observador conforme direção de visualização. É utilizado, portanto, como campo de visão, toda a meia esfera de Thiel (1997) e Teller (2003). O resultado fornecido pelo modelo do ArcGIS é constituído pelas linhas que ligam, sem obstruções, edificações de interesse visual e observadores. Para a verificação da existência dessas linhas de visão, são utilizados como referência apenas pontos do topo das edificações alvo, pois se pressupõe que a parte superior de um objeto é aquela com maior probabilidade de ser vista (Figura 9). 

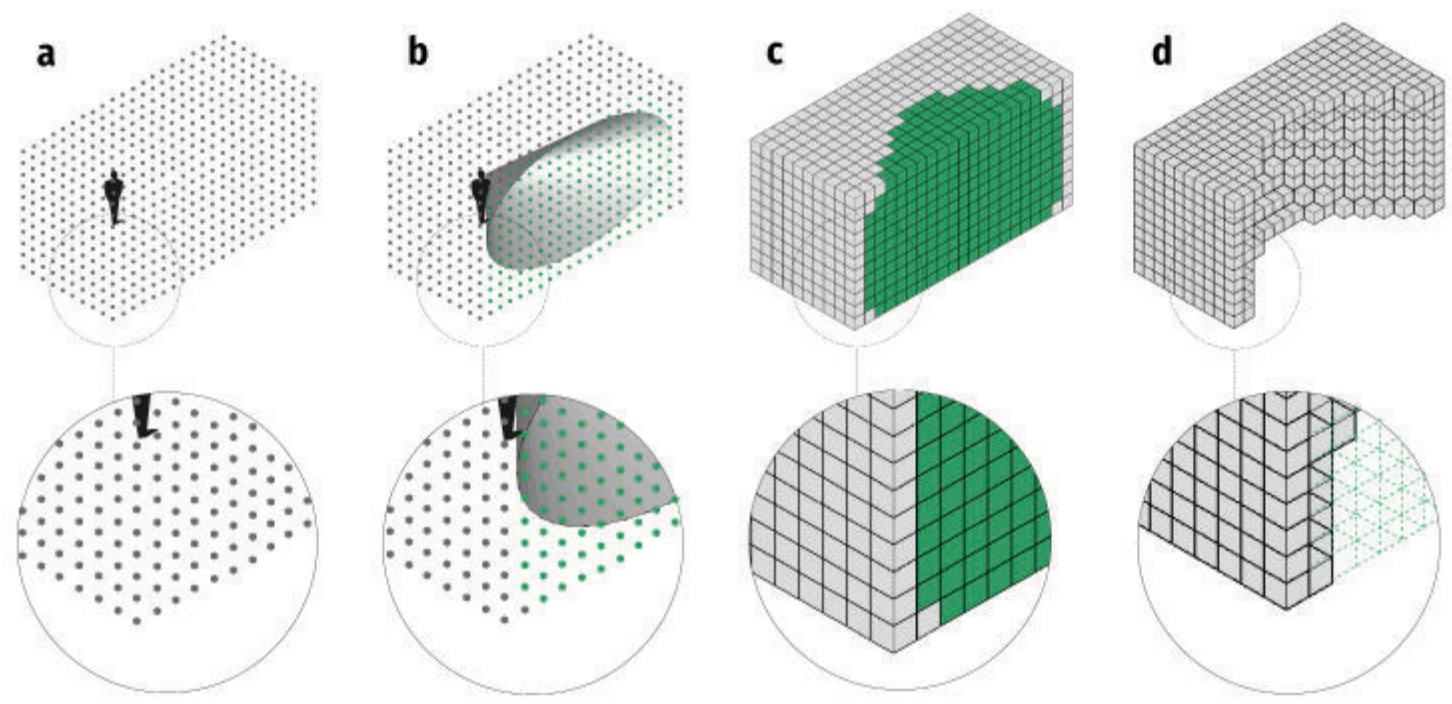

\section{- Cubo/Ponto Visível}

- Cubo/Ponto Ocluso

Figura 7: Isovista tridimensional: a) inserção de nuvem de pontos, b) diferenciação de pontos visíveis e oclusos, c) criação de módulos cúbicos a partir dos pontos, d) apenas cubos oclusos são representados.

Fonte: Elaborada pelo autor.
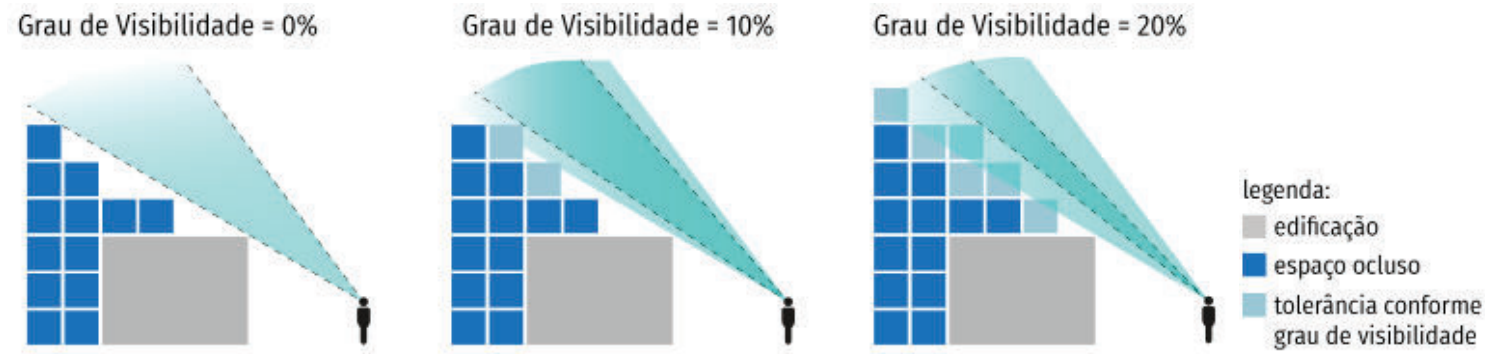

Figura 8: Definição de diferentes graus de visibilidade através da redução da amplitude do campo de visão.

Fonte: Elaborada pelo autor.

A comparação dos modelos apresenta o Cityzoom como o mais preciso, porque, por manipular o espaço vazio como entidades computacionais, ele possibilita a modelagem de volumes ocupando o limite do espaço em oclusão. Os softwares SIG não possuem tal capacidade, visto que neles o volume em oclusão é gerado da manipulação de superfícies, ação que implica a existência de vazios entre o volume ocluso e os limites visuais (Figura 10).

Há, também, diferenças na computação de recuos das fachadas das edificações, visto que, enquanto ArcGIS e Cityzoom geram volume ocluso adjacente ao limite do campo visual, CityEngine exige o recuo de toda a fachada da edificação até nenhuma região de sua superfície interseccionar o campo de visão do observador (Figura 11).

Como a visão do observador do ArcGIS é computada apenas através da conexão entre ele e as edificações de interesse visual, o software não "reconhece" objetos localizados na parte posterior de edificações alvo, permitindo a extrusão de volumes oclusos que, apesar de não bloquearem a vista, interferem na visualização de observadores (Figura 12). Cityzoom e CityEngine têm a capacidade de evitar a modelagem de volumes na parte posterior de objetos. 


\section{CityEngine}

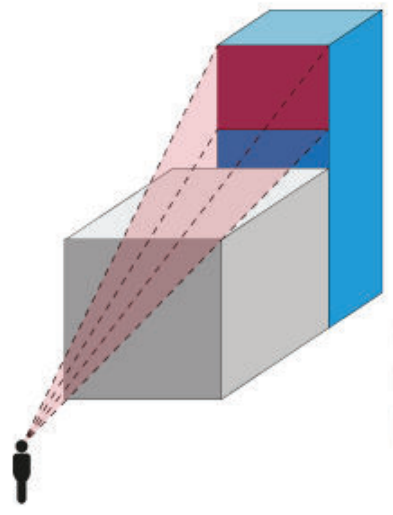

$\checkmark$ Volume existente

Volume simulado

Parte do campo visual que sofre interferência do volume simulado

\section{ArcGIS}

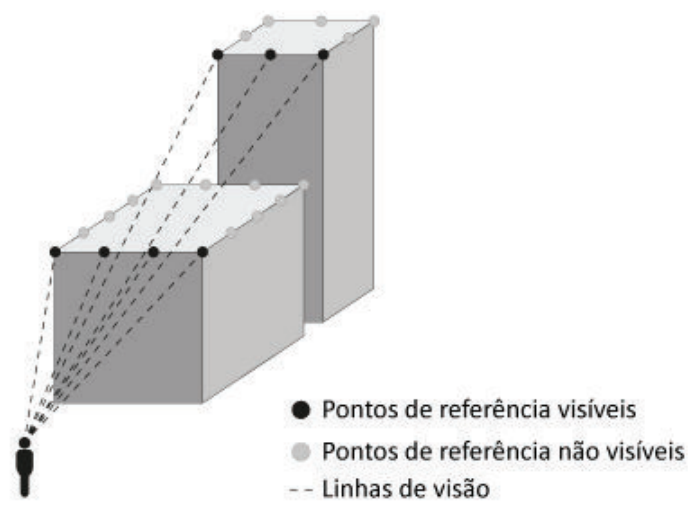

Figura 9: Modelo do CityEngine colore superfícies do modelo interferentes no campo de visão. Modelo do ArcGIS gera linhas de visão conectando observador e topo das edificações.

Fonte: Elaborada pelo autor.

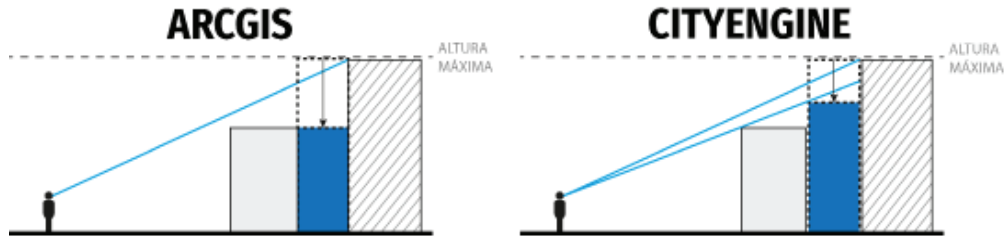

Figura 10: Diferença na computação da altura máxima dos volumes de oclusão. Fonte: Elaborada pelo autor.

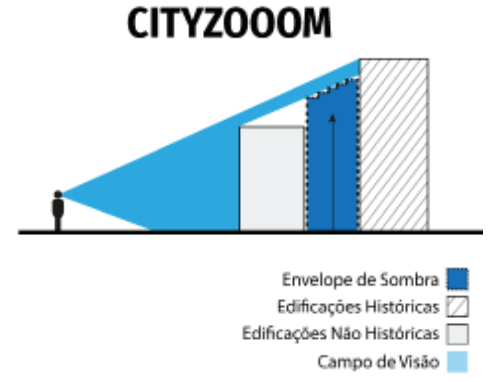

Envelope de Sombra

Edificaçóes Históricas Edificaç̧es Náo Históricas Campo de Visåo

Figura 11: Geração do volume ocluso no plano horizontal em cada software.

Fonte: Elaborada pelo autor.
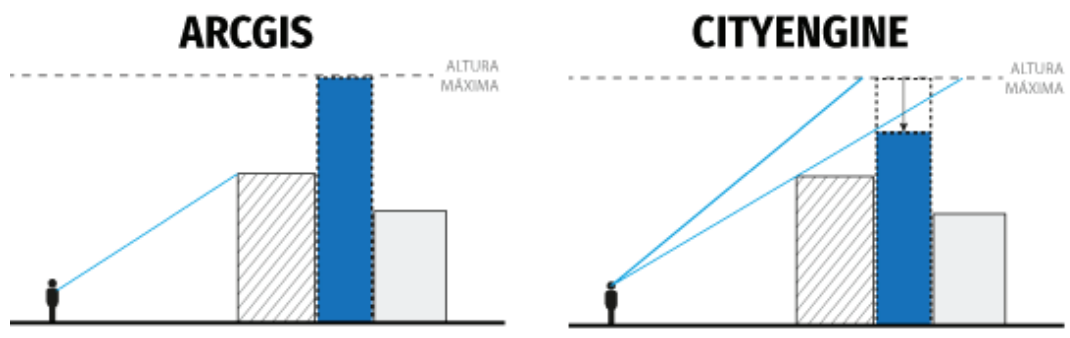

Figura 12: Geração do volume ocluso no plano vertical em cada software.

Fonte: Elaborada pelo autor.

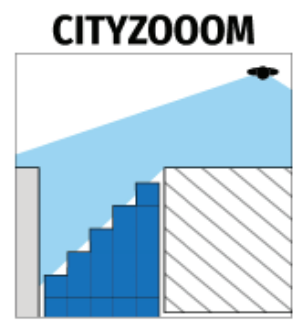




\section{MATERIAIS E MÉTODO}

A aplicação dos modelos de oclusão visual pode levar ao registro de espaços não visíveis a partir de diferentes posições de observação. Podem ainda ser utilizados para testar tolerâncias de visibilidade de novos objetos a partir da variação de percentuais de oclusão destes objetos. Dado que uma das principais variáveis que impactam a preservação da ambiência produzida por edificações de valor cultural refere-se à relação entre estas edificações e novos empreendimentos, torna-se fundamental caracterizar limiares de visibilidade para novos objetos. Com a caracterização, poder-se-ia: a) determinar o envelope de edificações potencialmente oclusas em relação a observadores presentes no espaço público; b) simular envelopes oclusos respeitando regras urbanísticas de altura e recuos em relação aos limites de lotes; c) simular diferentes graus de tolerância de visibilidade de novos objetos; e d) descrever o potencial construtivo dos cenários testados. Levando em consideração as especificidades dos modelos computacionais dos softwares ArcGIS, CityEngine e Cityzoom, três diferentes processos de análise visual foram utilizados na caracterização dos limiares de visibilidade de área urbana, em que são discriminadas edificações a terem visuais preservadas. O texto a seguir descreve os passos comuns e os processos específicos de cada software na configuração dos modelos de oclusão.

\section{Etapas do Processo}

Nos três softwares, o processo de configuração dos modelos inicia com a importação, em formato shapefile ou DXF, das camadas de informação correspondentes às curvas de nível, edificações existentes (em que as alturas e eventual importância visual devem ser fornecidas), parcelamento e, para o caso específico do Cityzoom, eixos viários. Posições de observação são inseridas ao redor de cada quadra analisada, simulando potencial percurso de um observador. Embora múltiplas combinações de posição e direção de visualização possam ser assumidas pelo observador, foi escolhido o campo de visão com maior abrangência, situado na calçada oposta à edificação observada com direção perpendicular a ela. Assim, a visão dos objetos situados na parte posterior da edificação alvo torna-se a mais abrangente (Figura 13).
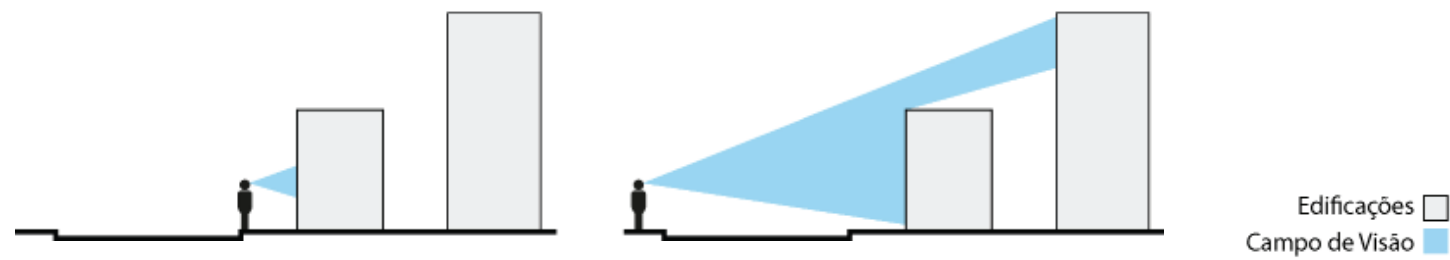

Figura 13: Afastando-se de um objeto, se obtém maior abrangência visual dos elementos em sua parte posterior.

Fonte: Elaborada pelo autor.

O ArcGIS não requer especificação de direção de observação, visto que seu modelo consiste de observadores com abertura do campo de visão ilimitado. Cityzoom e CityEngine necessitam da especificação dos ângulos vertical e horizontal do campo visual, os quais correspondem, respectivamente, a $90^{\circ}$ e $170^{\circ}$. Para estes dois softwares também é necessária a execução de comando de remoção de observadores sem contato visual com as edificações alvo: no Cityzoom, seleciona-se os lotes contendo edificações alvo e executa-se o comando Filter Observers by Visibility; no CityEngine, o usuário realiza conferência manual do que é visto de cada posição.

Nos softwares ArcGIS e CityEngine, a geração do volume ocluso requer a discriminação das áreas construíveis, correspondendo às áreas não edificadas e não contidas nos recuos mínimos obrigatórios conforme o Plano 
Regulador. No ArcGIS, gera-se a camada de áreas construíveis subtraindo da superfície dos lotes - com o comando Erase - as áreas já edificadas ou referentes a recuos mínimos. No CityEngine, pode-se desenhar os polígonos das áreas construíveis com a ferramenta de criação de polígonos ou importar arquivo shapefile gerado em software SIG. O software Cityzoom dispensa esta etapa porque reconhece automaticamente áreas ocupadas por edificações como não construíveis.

A geração do volume ocluso difere significativamente nos três softwares analisados. Em todos, ele é obtido através da extrusão dos polígonos referentes às áreas construíveis até que interseccionem os limites do campo visual de alguma posição de observação. As diferenças entre os modelos de cada software implicam em especificidades na execução de cada processo. No software ArcGIS, executa-se o comando Construct Sight Lines para as camadas contendo as posições de observação e as edificações alvo. Utiliza-se como parâmetros a altura dos olhos do observador igual a 1,70 metros e a distância entre pontos de amostragem igual a 1 metro. São obtidas as retas que conectam observadores e edificações de interesse visual (quadro 'a' da Figura 14), utilizadas como dado de entrada - em conjunto com a camada contendo o restante das edificações - para o comando Intervisibility, que verifica as linhas de visão geradas no comando anterior obstruídas por edificações existentes (quadro 'b' da Figura 14), linhas estas que são excluídas (quadro 'c' da Figura 14). Permanecem no modelo apenas as linhas das visuais existentes para edificações alvo, utilizadas como referência para extrusão dos volumes oclusos: polígonos que não conflitam com tais linhas de visão podem assumir a altura máxima permitida, visto que não afetam a visualização das edificações alvo; polígonos que conflitam com as linhas de visão assumem a altura da edificação situada entre ela e o observador, pois esta é a altura máxima que se pode garantir para que a extrusão não interfira a visão do observador - tal ação é necessária pois o ArcGIS computa apenas a existência de conexão entre observador e o topo das edificações, não fornecendo limites precisos do campo visual (quadro 'd' da Figura 14).
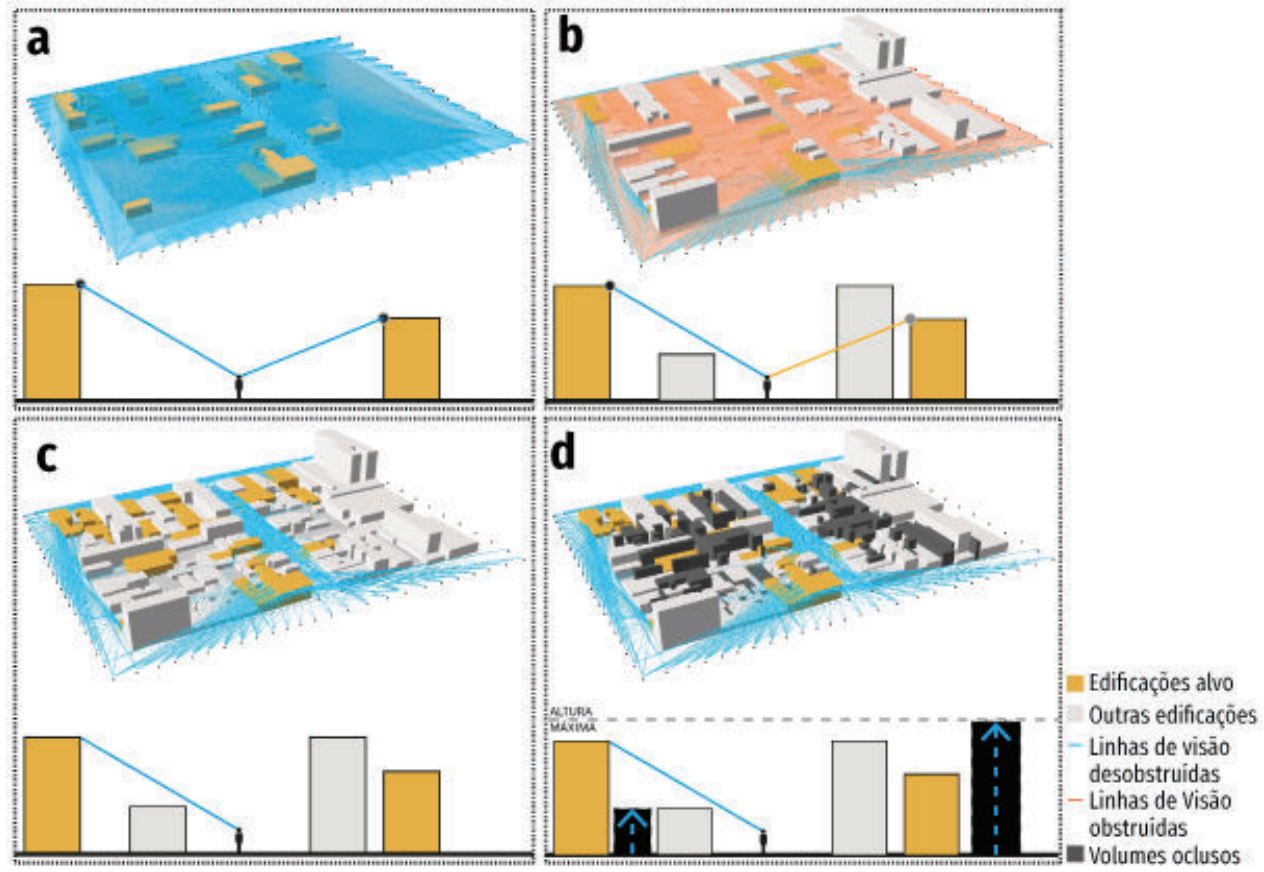

Figura 14: Geração de volume ocluso no ArcGIS: a) criação de linhas entre observadores e edificações, b) verificação das linhas obstruídas, c) exclusão de linhas obstruídas, d) extrusão de áreas construíveis.

Fonte: Elaborada pelo autor. 
No software CityEngine, os polígonos oclusos são extrudados até a altura máxima permitida para o lote (quadro 'a' da Figura 15) e os volumes resultantes são categorizados como um cenário projetual. Essa ação implica que as superfícies destes volumes que interseccionarem algum campo de visão serão destacadas em vermelho (quadro 'b' da Figura 15). A altura das extrusões é diminuída até que elas não interfiram em qualquer campo visual, sendo este resultado correspondente ao volume totalmente ocluso, portanto sem potencial interferência visual sobre o ambiente pré-existente (quadro 'c' da Figura 15).
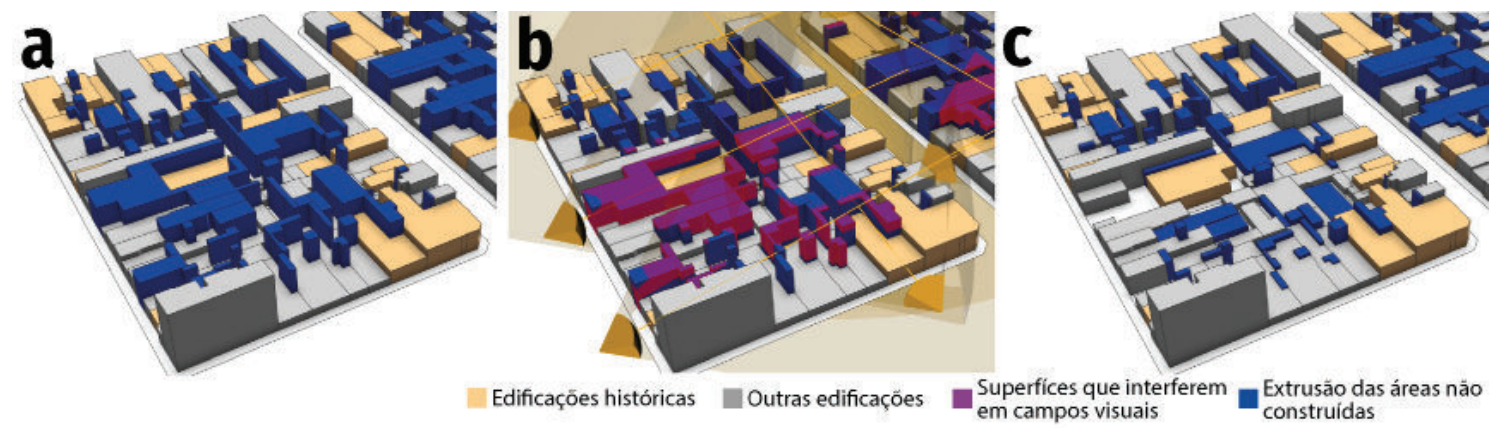

Figura 15: Geração do volume ocluso no CityEngine, a) extrusão de áreas construíveis até altura máxima permitida, b) verificação de volumes que interseccionam campo de visão dos observadores e c) diminuição da altura das extrusões até não possuírem regiões visíveis.

Fonte: Elaborada pelo autor.
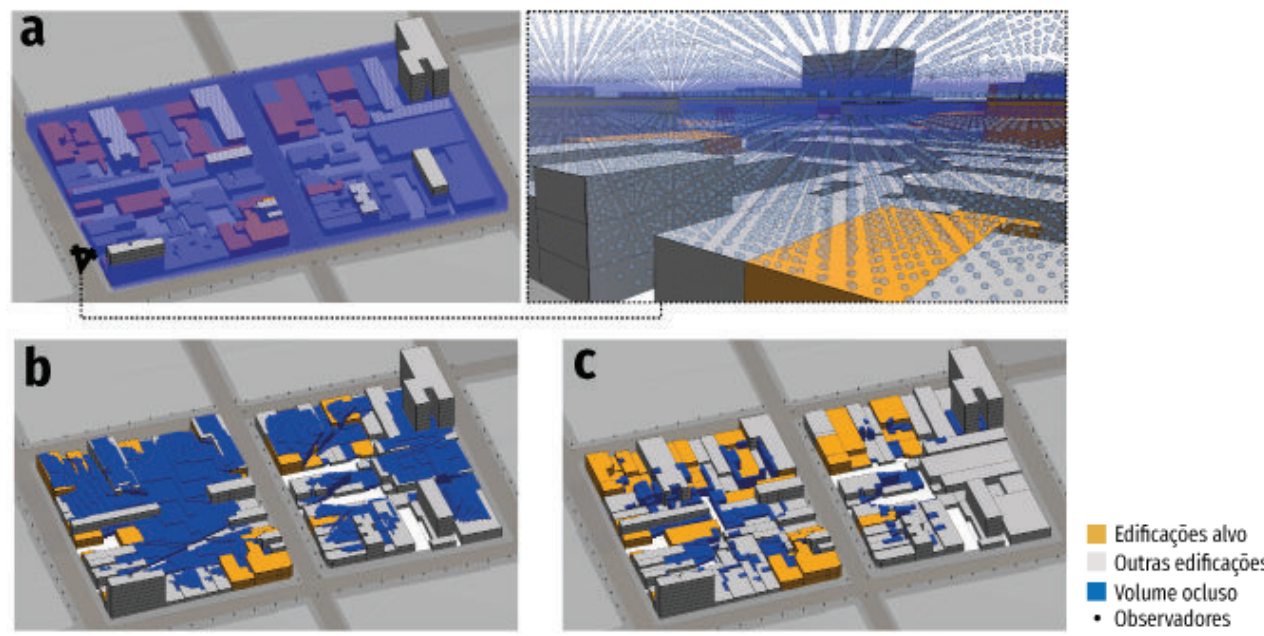

Figura 16: Geração do volume ocluso no Cityzoom: a) insere-se nuvem de pontos; b) pontos oclusos originam cubos; c) exclusão de cubos situados sobre edificações ou recuos mínimos.

Fonte: Elaborada pelo autor.

No Cityzoom, para a geração do volume ocluso, insere-se nuvem de pontos abrangendo a área de análise (quadro 'a' da Figura 16), ação feita através do comando Add Point Grid. Executa-se, então, o comando Occlusion Mesh, que computa os pontos da nuvem não vistos de qualquer posição de observação. Em torno destes pontos invisíveis são gerados cubos que representam o volume ocluso (quadro 'b' da Figura 16). Utiliza-se a ferramenta Voxel Exclusion para executar a exclusão de cubos oclusos localizados sobre edificações ou que desrespeitam regras urbanísticas (quadro 'c’ da Figura 16). 
Opcionalmente, pode-se simular diferentes graus de tolerância para a visibilidade do volume ocluso. No Cityzoom, essa ação é realizada alterando o valor do parâmetro Visibility Level. Nos softwares ArcGIS e CityEngine, não há ferramenta específica que simule tal grau de visibilidade, exigindo configuração manual da altura dos volumes oclusos ou dos parâmetros do campo de visão do observador. A representação da visão do observador pode ser acessada automaticamente em Cityzoom e CityEngine através da seleção da posição cuja visual se deseja obter. ArcGIS, por outro lado, exige que a visualização seja manualmente configurada para simular alguma das posições de observação.

Para obter medidas quantitativas do potencial construtivo do volume ocluso, executa-se comandos específicos em cada software. O ArcGIS requer que o usuário tenha noções de manipulação de planilhas, pois as medidas são obtidas por comandos matemáticos. No CityEngine, é necessário que o usuário tenha a capacidade de escrever comandos em forma de código procedural para que o programa retorne dados numéricos de qualquer elemento do modelo. O Cityzoom, por sua vez, exige apenas a utilização do comando Update Information, que resulta na apresentação das medidas de volume e área de projeção da volumetria oclusa desagregadas por lote.

ArcGIS

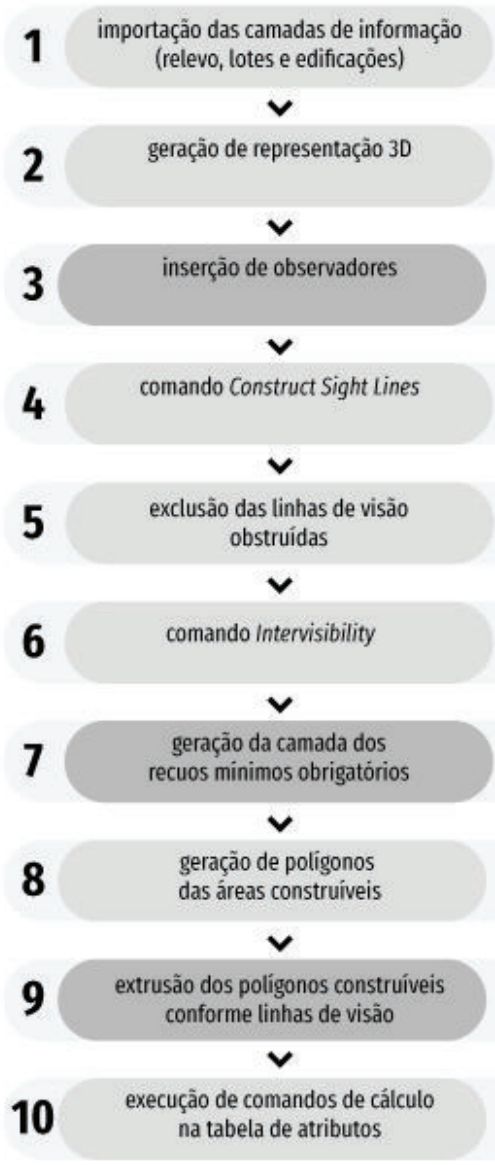

\section{CityEngine}

importação das camadas de informação (relevo, lotes e edificações)
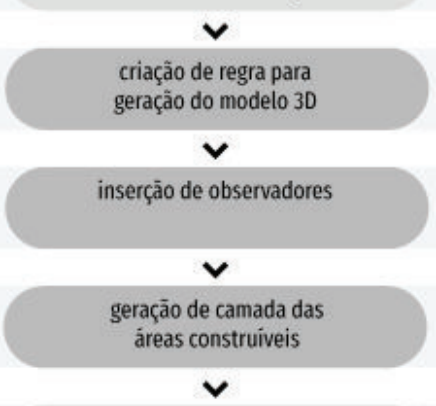

criação de cenário contendo a extrusão dos poligonos construiveis

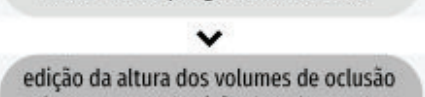
conforme campo de visào dos observadores

execuçāo de comandos de cálculo para a camada de volume de oclusão

obtenção de informaçōes numéricas do volume de oclusão

\section{Cityzoom}

importação das camadas de informaçăo (relevo, vias, quadras, lotes e edificaçōes)

geração do modelo tridimensional de observação

inserçāo de nuvem de pontos

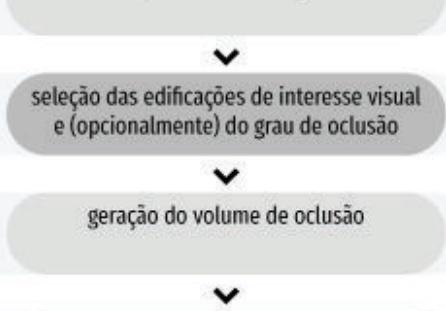

(opcional) aplicação de filtro para remoção de cubos conforme sua situação

obtenção de informaçôes numéricas do volume de oclusão

tarefas que necessitam repetição manual de uma mesma tarefa

Figura 17: Etapas necessárias para execução de cada método de análise de oclusão.

Fonte: Elaborada pelo autor. 
A Figura 17 apresenta diagrama com a sequência de etapas necessárias em cada software para a geração do volume ocluso construível e obtenção de medidas quantitativas referentes ao potencial construtivo desse volume. São destacadas em cor escura as ações que necessitam repetição manual de um mesmo comando, pois estas se configuram como as etapas mais demoradas dos processos. Observa-se que Cityzoom e CityEngine apresentam sequências com menos etapas do que o ArcGIS, com o Cityzom também apresentando menos ações de repetição manual. Esse desempenho mais eficiente do Cityzoom ocorre, principalmente, porque suas ferramentas apresentam aplicação definida, oferecendo, em troca dessa limitação, a automatização dos processos necessários para sua execução. ArcGIS e CityEngine possuem estrutura que permite a combinação das ferramentas existentes de diversas formas, abrangendo uma diversidade maior de aplicações. Essa fragmentação, porém, impede que a automatização de sequências procedurais, tornando sua execução mais demorada que aplicativos elaborados especificamente para um fim.

\section{Estudo de Caso}

ArcGIS, CityEngine e Cityzoom foram utilizados em estudo de caso em quadras do Centro Histórico de Pelotas (Figura 18), município do Rio Grande do Sul e que possui o maior conjunto de edificações listadas como de valor cultural no Estado. Por suas características urbanísticas singulares, o Centro Histórico de Pelotas apresenta potencial para aproveitamento turístico e cultural onde alterações morfológicas poderão impactar, negativamente, a ambiência existente. Faz-se necessário, portanto, que intervenções arquitetônicas sejam feitas de forma criteriosa e a representação do volume ocluso é um possível referencial para garantir a predominância visual de edificações históricas em relação a novos empreendimentos.

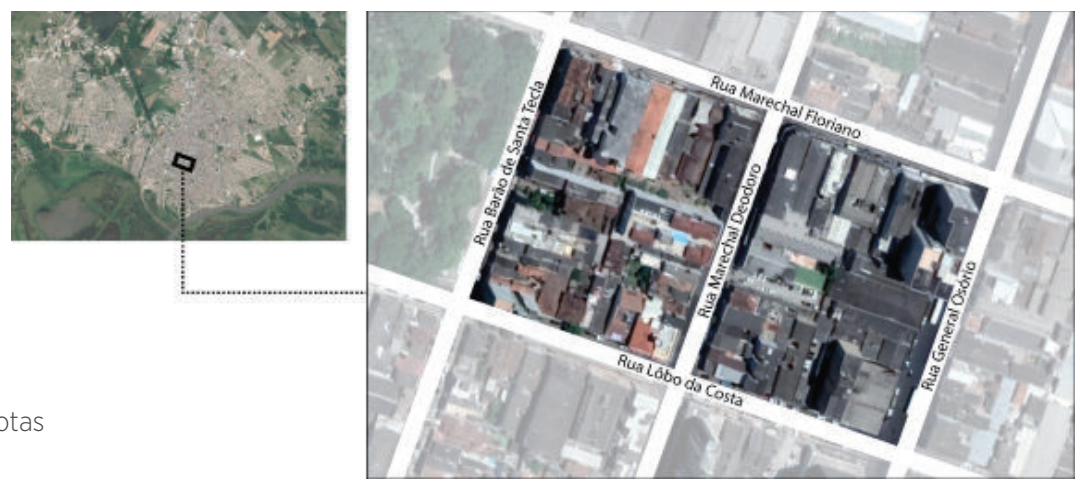

Figura 18: Área de estudo em Pelotas

Fonte: Google Earth, 2018.
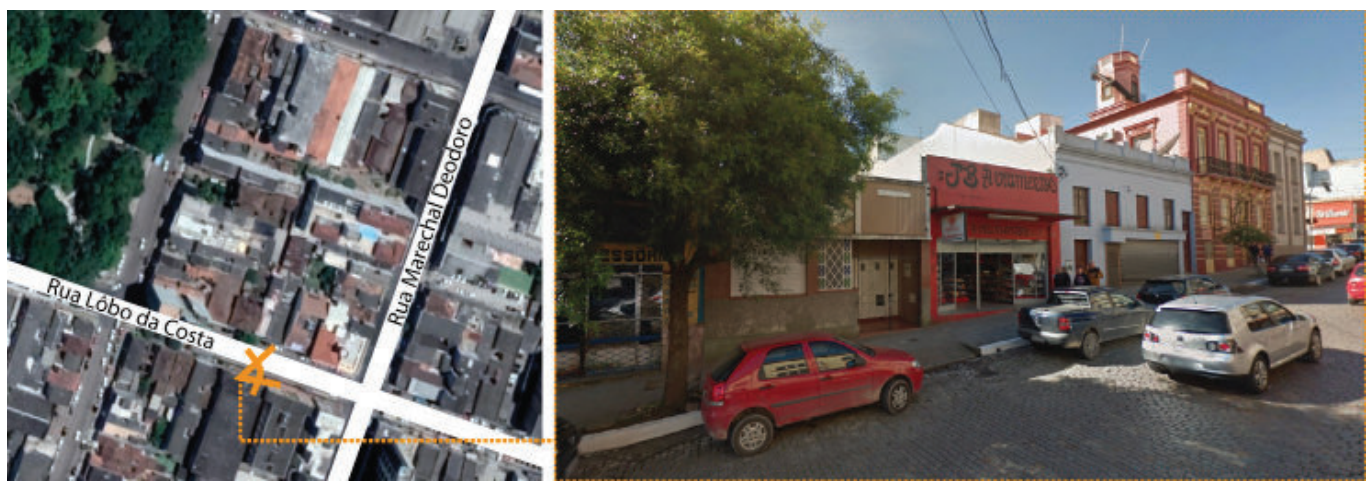

Figura 19: Localização da perspectiva apresentada nos resultados do estudo de caso.

Fonte: Google Earth, 2018. 
Os processos elaborados para cada software foram executados com o objetivo de: a) aferir o volume totalmente ocluso passível de ser construído, b) simular diferentes graus de visibilidade tolerada para esse volume e c) medir quantitativamente o potencial construtivo de todos esses cenários. Como alvos visuais das simulações, foram utilizadas as edificações listadas em inventário consolidado pela Lei Municipal referente ao Plano Diretor do município (PELOTAS, 2008). Como a área de estudo se insere dentro da zona do Plano Regulador denominada Zona de Preservação do Patrimônio Cultural, incidem em seus lotes os seguintes limites: altura máxima de 10 metros - exceto para terrenos com testada maior que 10 metros, para os quais se permite altura de até 13 metros - recuo mínimo de fundos igual a 3 metros e isenção de recuos frontal e lateral.

A representação dos resultados é constituída por: a) vista geral, na qual visualiza-se a quase totalidade do volume simulado, b) simulação da perspectiva de um transeunte para diferentes graus de visibilidade do volume ocluso e c) medidas numéricas do potencial construtivo do espaço em oclusão. A perspectiva do transeunte considera posição de observação situada na rua Lôbo da Costa (Figura 19), escolhida por permitir a visualização de exemplares históricos de baixa altura, os quais são mais propensos a sofrerem com a predominância visual de edificações próximas.

Os resultados da Figura 20 indicam semelhança dos modelos icônicos dos softwares, visto a similaridade das perspectivas do ponto de vista do observador. A acurácia da computação dos espaços oclusos, entretanto, não é igual, como indica a diferença entre valores das medidas quantitativas (Tabela 1). Os valores de volume para o espaço ocluso são maiores para o ArcGIS porque seu modelo permite a geração de volumes na parte posterior dos objetos alvo. CityEngine, por outro lado, apresenta resultados mais restritivos devido a imprecisões na computação tanto da altura quanto do recuo das fachadas das volumetrias oclusas. Essas imprecisões implicam que o volume ocluso resultante não ocupa todo o espaço que não é visível. Cityzoom apresenta valores intermediários em relação aos outros softwares por não apresentar tais aspectos causadores de falta de acurácia na modelagem da volumetria oclusa.

\begin{tabular}{|c|c|c|c|}
\hline & ArcGIS & CityEngine & Cityzoom \\
\hline Grau de visibilidade 0 & $40.226,4 \mathrm{~m}^{3}$ & $25.433,09 \mathrm{~m}^{3}$ & $30.419,9 \mathrm{~m}^{3}$ \\
\hline Grau de visibilidade 3 & $47.342,7 \mathrm{~m}^{3}$ & $33.902,04 \mathrm{~m}^{3}$ & $40.372,8 \mathrm{~m}^{3}$ \\
\hline Grau de visibilidade 5 & $54.459,1 \mathrm{~m}^{3}$ & $39.547,95 \mathrm{~m}^{3}$ & $50.981,10 \mathrm{~m}^{3}$ \\
\hline
\end{tabular}

Tabela 1: Volume do espaço ocluso nas simulações realizadas.

Fonte: Google Earth, 2018. 


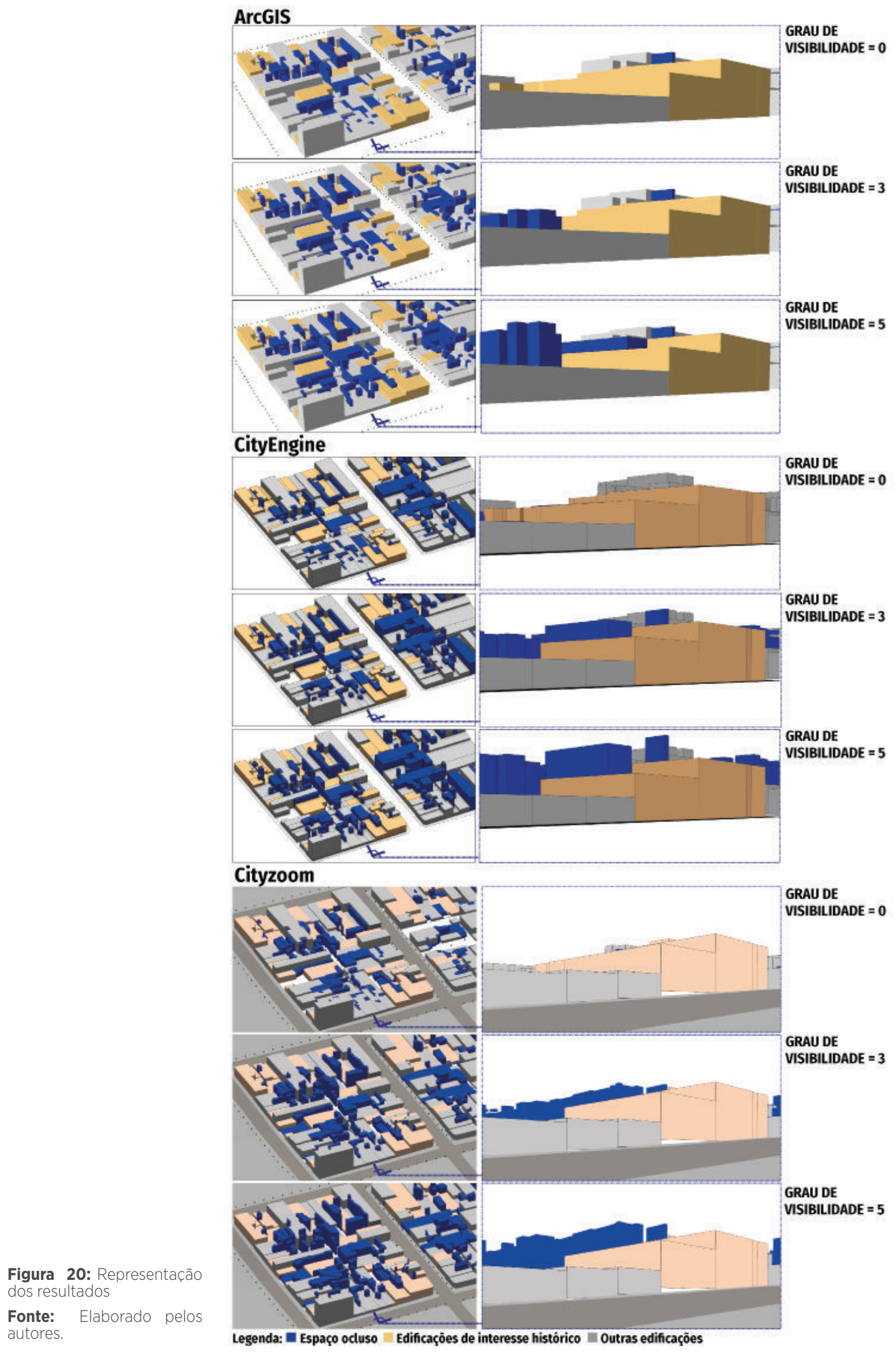




\section{CONCLUSÕES}

Este trabalho descreve funcionalidades dos softwares ArcGIS, CityEngine e Cityzoom que podem oferecer suporte à aferição de volumes potencialmente oclusos em quadras configuradas por conjuntos históricos e à simulação de diferentes graus de visibilidade tolerada para estes volumes. A partir da análise de seus modelos, processos foram elaborados para cada software e testados em estudo de caso para o Centro Histórico do município de Pelotas. Os resultados indicaram a semelhança dos modelos icônicos de simulação, mas também diferenças na rapidez de execução dos processos e no valor dos resultados numéricos obtidos das simulações.

Cityzoom apresentou sequência de utilização mais rápida devido à automatização de procedimentos existentes no programa. Softwares SIG apresentam ferramentas em estrutura desagregável, com objetivo de tornarem-se acessíveis a uma diversidade de aplicações. Essa abrangência resulta em menor integração entre comandos e menor automatização de processos, tornando a execução mais demorada. Tal rapidez torna Cityzoom ferramenta ágil para formular conjeturas em situações de confronto de opiniões sobre impactos causados por novas edificações em ambientes urbanos.

Cityzoom também apresentou maior acurácia na computação do volume ocluso. As medidas quantitativas obtidas no estudo de caso realizado mostraram que ArcGIS fornece resultados mais permissíveis por não considerar como oclusos objetos situados na parte posterior de edificações alvo. CityEngine gera volumes oclusos demasiadamente restritivos, visto que deixa desocupadas regiões não visíveis para o observador. Tendo em vista tais resultados, pode-se considerar Cityzoom o software que, dentro os analisados, disponibiliza potenciais construtivos mais elevados em áreas caracterizadas por restrições construtivas sem exceder o envelope ocluso local.

\section{AGRADECIMENTOS}

O presente trabalho foi realizado com apoio do Mec/MinC (Projeto Representação e Simulação do Patrimônio Construído - Edital 07/2008 - Pró-Cultura), da Coordenação de Aperfeiçoamento de Pessoal de Nível Superior - CAPES (Projeto 028.20/09-9) e da Universidade Federal do Rio Grande do Sul (Projeto B.E.S.T. $-\mathrm{n}^{\circ}$ 28932). Os autores agradecem a essas instituições.

\section{REFERÊNCIAS}

ARCGIS. Esri ArcGIS: Overview. [S.I], 2018. Disponível em: https://www.esri. com/en-us/arcgis/about-arcgis/overview. Acesso em: 12 dez. 2018.

ALMEIDA, A.; GONÇALVES, L.; FALCÃO, A.; ILDEFONSO, S. 3D-GIS Heritage City Model: case study of historical city of Leiria. In: AGILE INTERNATIONAL CONFERENCE ON GEOGRAPHIC INFORMATION SCIENCE, 19., 2016, Helsinki, SE. Anais eletrônicos [...]. Dresden, DE: Association of Geographic Information Laboratories in Europe (AGILE), 2016. Disponível em: https://agile-online.org/ conference_paper/cds/agile_2016/ shortpapers/113_Paper_in_PDF.pdf.
Acesso em: 7 maio 2019.

BATTY, Michael. Exploring Isovist Fields: Space and Shape in Architectural and Urban Morphology. Environment and Planning B Planning and Design, v. 28, p. 123-150, 2001. http://dx.doi. org/10.1068/b2725

BENEDIKT, MICHAEL, To Take Hold of Space: Isovists and Isovist Fields; Environment and Planning B Planning and Design, v. 6, p. 47-65, 1979. http://dx.doi. org/10.1068/b060047

CÂMARA, G. E DAVIS, C. Introdução à Ciência da Geoinformação. São José dos Campos: INPE - Instituto Nacional 
de Pesquisas Espaciais, 2001.

CITYENGINE. CityEngine: Advanced 3D city design software. [S.I], 2018. Disponivel em: https://www.esri.com/ en-us/arcgis/products/esri-cityengine/ overview. Acesso em: 12 dez. 2018.

DALTON, R.; DALTON, N. The Problem of Representation of 3D Isovists. In: INTERNATIONAL SPACE SYNTAX SYMPOSIM, 10., 2015, Londres, GB. Anais [...]. Londres, GB: University College of London, 2015. p. 141:1-18.

ESCORTEGANHA, M.; SANTIOGO; A.; BAYON, J.; BILAL, E. Percepção da Utilização do Geoprocessamento e a Fotogrametria na Preservação do Patrimônio Cultural. In: CONGRESSO BRASILEIRO DE CADASTRO TÉCNICO MULTIFINALITÁRIO E GESTÃO TERRITORIAL, 10. 2012, Florianópolis. Anais Eletrônicos [...]. Florianópolis: UFSC. Florianópolis, 2012. Disponível em: https://hal.archives-ouvertes.fr/hal-00806883/document. Acesso em: 7 maio 2019

FRACCAROLI, C. A percepção da forma e sua relação com o fenômeno artístico: o problema visto através da Gestalt. São Paulo: FAUUSP, 1982.

INSTITUTO DO PATRIMÔNIO HISTÓRICO E ARTÍSTICO NACIONAL (IPHAN): Normatização de Cidades Históricas: orientações para a elaboração de diretrizes e Normas de Preservação para áreas urbanas tombadas. Brasília: IPHAN, 2011.

INSTITUTO DO PATRIMÔNIO HISTÓRICO E ARTÍSTICO NACIONAL (IPHAN). Portaria $n^{\circ} 10$, de setembro de 1986.

PELOTAS. Lei $\mathbf{n}^{\circ} \mathbf{5 5 0 2}$, de 11 de setembro de 2008. Institui O Plano Diretor municipal e estabelece as diretrizes e proposições de ordenamento e desenvolvimento territorial no município de Pelotas, e dá outras providências.

SANDER, H.; MANSON, M.; Heights and locations of artificial structures in viewshed calculation: How close is close enough? Landscape and Urban Planning, v. 82, ed. 4, p. 257-270, 2007.

SIQUEIRA, C. Preservação e Renovação Urbana no Recife: uma dialética nos imóveis especiais de preservação. Orientador: Pedro Henrique Valadares. 2017 Trabalho de Conclusão de Curso (Graduação em Arquitetura e Urbanismo) Faculdade Damas da Instrução Cristã, Recife, 2017.

TELLER, J. A spherical metric for the field-oriented analysis of complex urban open spaces. Environment and Plan- ning B: Planning and Design, v. 30, p. 339-356, 2003

TEODORO, T.; GOMES, H.; HEIDRICH, F.; SILVA, A. Otimização de Modelos Digitais para Visualização de Patrimônio Histórico-Arquitetônico em Realidade Aumentada. In: CONGRESSO DA SOCIEDADE IBEROAMERICANA DE GRÁFICA DIGITAL - SIGRADI, 16., 2012, Fortaleza. Anais [...]. [S.I.: s. n.], 2012. v.1. p. 423425.

THIEL, P. People, paths, and purposes: Notations for a participatory envirotecture. Seattle: University of Washington Press, 1997.

TURKIENICZ, B.; GONÇALVES, B. G.; GRAZZIOTIN, P. CityZoom: A Visualization Tool for the Assessment of Planning Regulations. International Journal of Architectural Computing, p. 79 - 95, jan. 2018. http://dx.doi. org/10.1260/147807708784640144.
Benamy Turkienicz

Guilherme Kruger Dalcin

Rodrigo Pereira Lersch

Renato Silveira 